\title{
Prevalence of melancholy in swat valley, Pakistan
}

\begin{abstract}
Melancholy is major mental challenges that is characterize by sadness, sleep disorder, decrease energy, etc. It also have a great social and mental consequences, it is well know that depression will be the second largest cause of disability globally till 2020. The risk are even higher in developed countries. According to world health organization globally it effect more than 121 million people. Depression is a complex and multi-dimensional anarchy according to it has many faces and cannot be describing by one simple formula because it originate from numerous complex mechanism. Multi-faced nature of depression makes it difficult to find out its etiology. The purpose of this study is to find out the prevalence of melancholy in different age groups and genders in district Swat. Overall 300 samples were collected randomly across different age groups and genders in which we found the prevalence of melancholy were $48.3 \%$ in which male depressed individual were $27.6 \%$ while female depressed were $20.6 \%$. The number of depressed individual were maximum in age group vary from $10-20$ which is $15 \%$. To conclude depression is easily manageable but it need understanding that how to control your feeling and thought and think new and positively.
\end{abstract}

Keywords: melancholy, sadness, sleep disorder, swat, Pakistan
Volume 6 Issue 4 - 2021

\author{
Suliman,' Arshad Kabir,' Zahid Iqbal,' Anwar \\ Ali, ${ }^{2}$ Sadam Hussain,' 'Naseer Ullah,' Kausar \\ Saeed, ${ }^{3}$ Muzafar Shah' \\ 'Centre for Animal Sciences \& Fisheries, University of Swat, \\ Pakistan \\ 2Department of Biochemistry, Saidu Medical College, Pakistan \\ ${ }^{3}$ Department of Zoology, University of Buner, Pakistan
}

Correspondence: Muzafar Shah, Centre for Animal Sciences \& Fisheries, University of Swat, Pakistan, Tel +92-3339348044, ORCID 0000-0002-5069-0228, Email muzafar@uswat.edu.pk

Received: June 10,2021 | Published: August 09, 2021

\section{Introduction}

Depression is one of the major mental challenges characterized by sadness, Loss of pleasure, low self-worth, sleep disorder, decrease energy and poor attention. ${ }^{1}$ Depression also have a social, health and mental consequences. ${ }^{2}$ It is thought that, depression will be the second largest cause of disability globally till 2020 and the risk are even more higher in developed countries (American Psychiatric Association. ${ }^{3}$ According to world health organization depression affect 121 million across the globe. Depression is a complex and multi-dimensional anarchy according to Warned, ${ }^{4}$ it has many faces and cannot be describing by one simple formula because it originate from numerous complex mechanism. Multi-faced nature of depression it difficult to find out its etiology. ${ }^{2}$ There are certain biological factor, e.g genes deregulate neurotransmitter. ${ }^{5}$ It is also known that genetic component also involved in depression, but exactly it is not known that what gene are responsible. Studies indicate that heredity is also a key factor that surrounding increase or decrease threat of mental illness. ${ }^{6}$ One of the biological theories on depression suggests that it result from brain neurotransmitter and hormone malfunctioning (serotonin, dopamine, adrenaline).

The concentration of this hormone is high in limbic system, connected with sleep regulation, hunger, thirst and other psychological process .many depressed individual have disturb hormonal level that manage body reaction against stress. High level of hormone such as cortisol and other stress hormone in their body are at the higher risk of depression. ${ }^{2,4}$ According to Sigmund Freud depression begins in grief reaction that is not recovered. Depressed individual display self-hate and self-blame. They without thinking harsh yourself, they sense isolated from people.depression is a sort of aggression directed toward transposed image by anyone who is in ambivalent and intense relationship with other people suffering from depression fail to express anger feeling clearly and have low self-esteem. ${ }^{7}$ In psychoanalytic terms depression is the imbalanced in capacity of ego for self-love, there are many arguments about the cause of depression, some says that phenomena of depression is purely psychological ,deal by psychotherapy, while few consider it biochemical that would treat with antidepressant drug, according to third school of thought blood sugar imbalances , lack of precursor amino acid for serotonin and nor adrenaline such as tryptophan ,lack of B vitamins (vitamin $\mathrm{B}_{6}$ folate, $\mathrm{B}_{12}$ ), lack of essential fat (omega-3). ${ }^{7-10}$ The cognitive approach to depression can be explain as a harmful image of self, depressing expectations about future and negative feeling about world and this is term cognitive triad. ${ }^{11,12}$

Whatever the person according to behaviorist school of thought that repeated experiences with unwanted lead a person to develop learned helplessness and expect that future event will be uncontrollable. ${ }^{13}$ Discomfort lead to minimum re enforcement that increases stress mean that less number event, that provide less positive belief. Depression is the reaction to stressful negative events. ${ }^{14}$ The reason is that stress reduce the level of positive reinforcement. ${ }^{15,16}$ The level of positive events depend upon these events in the environment, if an individual can't sustain balance between positive and negative events results in to high level of self-awareness that will lead to self criticism. ${ }^{17}$ We know that imagination of future cynical event can have consequences over psychological being have a role in reduce the recovery from depression and persistence's. ${ }^{18}$ Threat of depression are usually high at the transition, state from child-hood to adolescence, more specifically in the young adult. ${ }^{19}$ The leading cause of death among young depressed adults is suicide. ${ }^{20}$ Studies have shown that $35-40 \%$ adolescent population are effected by depression a close overview, one among every five may suffer from depression. ${ }^{21}$ Depression in adolescents is not easy to identify, some younger chikdren, pretended to be sick, worry about their parent death, older children do not participate in family and social activities, use drugs and stop paying attention to their appearance, Center for Mental Health Services. ${ }^{22}$ According to American psychological association there must be a difference between depression and occasionally feeling sad or worry these felling must be temporary and must be passes very quickly, In the contrary someone having depression experienced extreme sadness 
that at least remain for two weeks or longer than that ,Usually these feeling interfere with normal everyday life activity and tend to stop participating every day normal life activity along with that withdraw yourself from society sometimes also have suicidal thoughts. Depression is a link with other disease's either directly or $\mathrm{h}$ stress indirectly but its relation to stress and anxiety are found to be more high $56 \%$ of patient meeting criteria for anxiety also meet criteria for depression. ${ }^{23}$ It has been said, that depressive symptom is invariably associated wits. ${ }^{24}$

\section{Material and method}

A questioner was developed to find out prevalence of depression in north of Khyber Pakhtunkhwa, district Swat tehsil Khawazakhela for a period of 6 months between January to June 2017. The geographical coordinates of Khawazakhela are $34^{\circ} 56^{\prime} 1^{\prime \prime}$ North, 72 $28^{\prime}$ 0" East. This thesil contain many union council including shin, shalpin, kotanai, miandam, jano, fathepur (Figure 1).

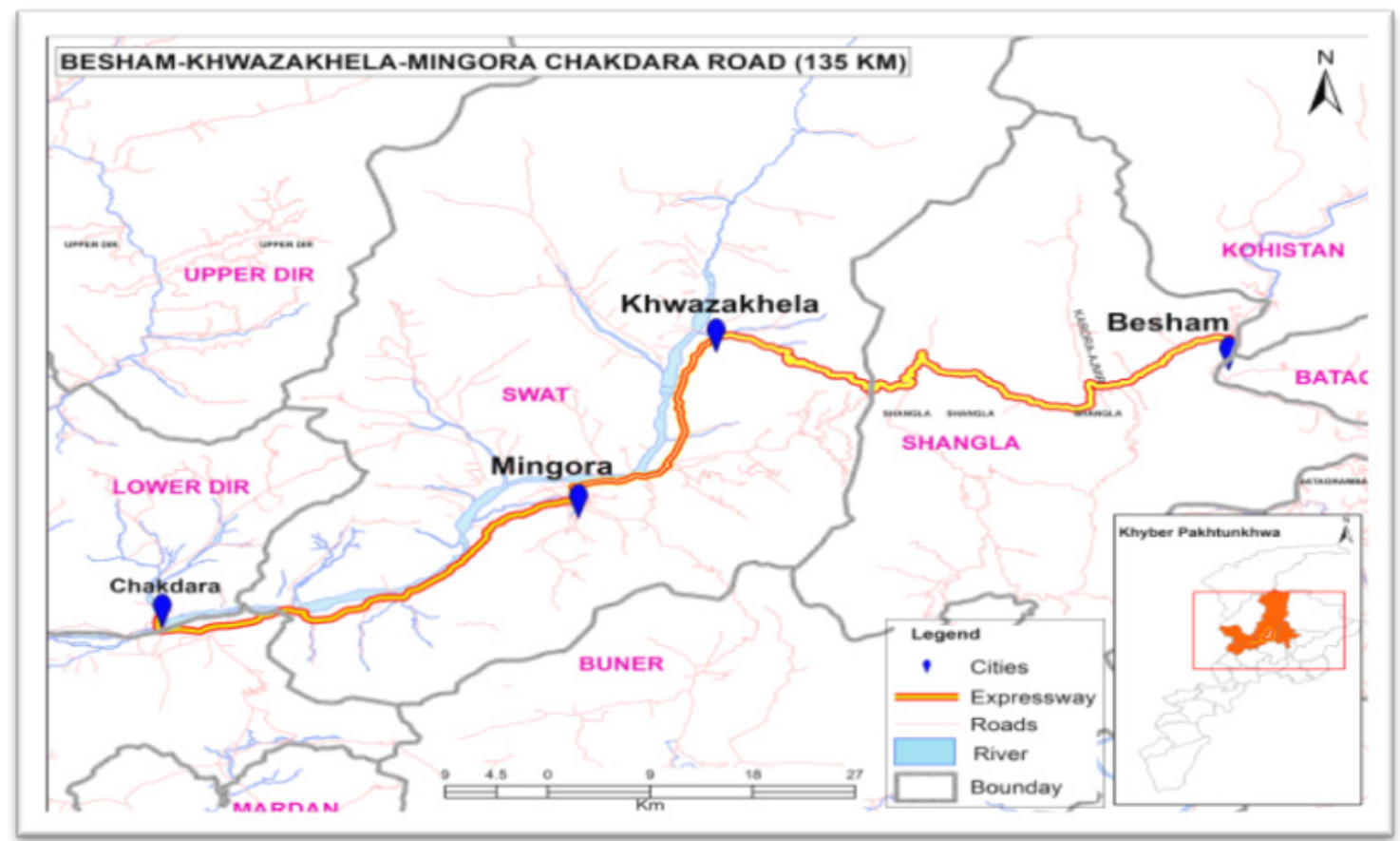

Figure I Map of Tehsil khwazakhela.

A questioner was designed to find out the prevalence of depression randomly across different age group, in this questioner we specifically asked about the symptoms of depression along with family history to find out the genetics of depression, by asking a special question that as you have anyone in your family suffering from depression or any other mental disorder and do specify the relation to patient.

Furthermore, they were asked that how often a person feels depressed and hopeless, the patient of depression either get very little or more sleep that's why it is also asked that whether individual getting too much are too little sleep along with the closing of individual weight. According to scientific literature, the depressed patient also has had very little energy and mostly interested In being alone along with that it is very hard for them to make a decision and do a simple task.

After all depressed patient has consistent destructive thoughts to find out this it is asking about thoughts of committing suicide and the degree of difficulty in making decision Furthermore it also mentions to find out whether the person fell any sort of guilty for that he wants punishment.

Different variable also have been mention in form of age, gender, marital status etc to link these variable with intensity of depression in an individual.

\section{Procedure}

The protocol followed for collecting data are home to home survey and mostly data are collected in formal friend meetings, visits to the busiest shops of villages to which in most of the case every person in village visit, the questionnaire were filled by investigator for most of the people and aged men and women who either didn't understand them or problem in their vision. The sample size was 300 , the median of which are 150 . They all are not collected at once but rather it takes a period of one month to get data from every village in this tehsil.

\section{Data interpretation}

First all data were collected and then interpreted with excel (2007) and Spss (16.0)

\section{Results}

This study were carried out to find out quantity and quality of depression among different age groups and their relation to other variable like Martial status, employment and across different gender. All questioners were filled from different villages of tehsil khawaza khela . Out of the entire respondent all females were (106) while male were (194) (Figure 2). 
194

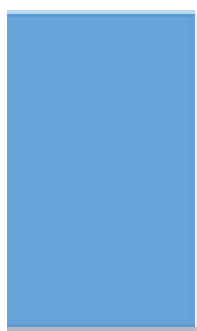

male

Figure 2 Total number of samples.
Furthermore marital status were also evaluated in the questionnaire to find out the number of married and un married individual and their relation to depression in which we found that $55 \%$ individual were not married and $45 \%$ were married. In addition to marital status the number of employed and un employed were also found that out of total 300 hundred participant $95 \%$ of individual were unemployed and $5 \%$ were employed.

We also focus on the level of depression in different in different age groups in which we make four groups the age vary between 10 to 20 are considered teen, while 20 to 35 are young adult and onward from 35 up to 50 are middle age people, then people having age of onward 50 are considered old age. The number of participants in these entire group vary showing in graph below Figure 3.

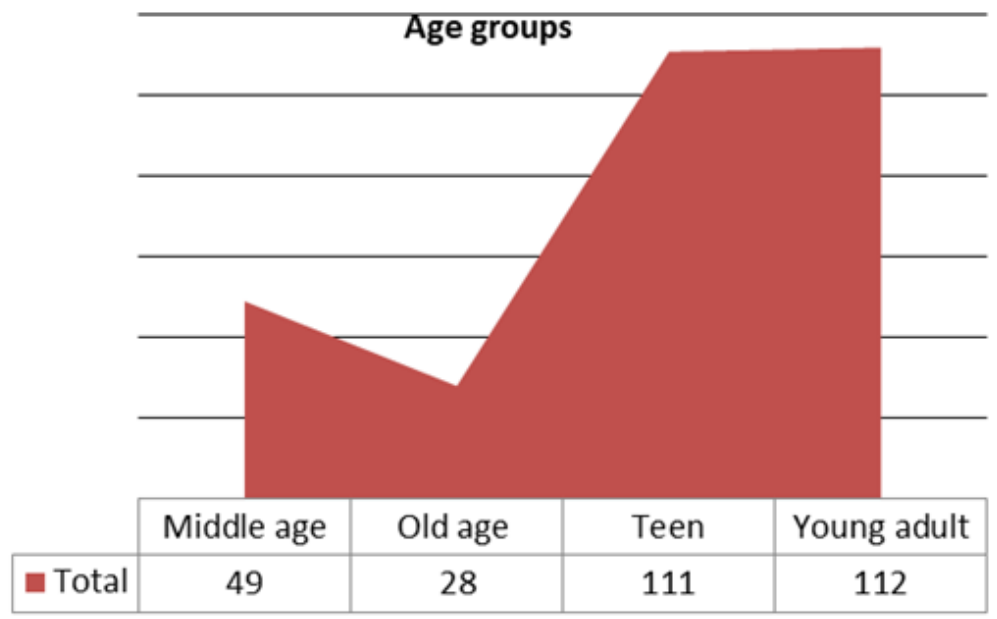

Figure 3 Different age groups.

We asked about depressed feeling, people responded differently either they does not feel depressed at all or some of the time or good part of time or all of the time showing below different ranges (Figure 4). We also know that people suffering from any kind of depression belong to any gender may also experience feeling of hopeless most of time hence we asked about hope and give us result below (Figure 5). Then we focused on different question about difficulty of any task, decision making, sleep and level of concentration and we found different percentages in all of these questions. we found different results given below (Figures $6 \& 7$ ).

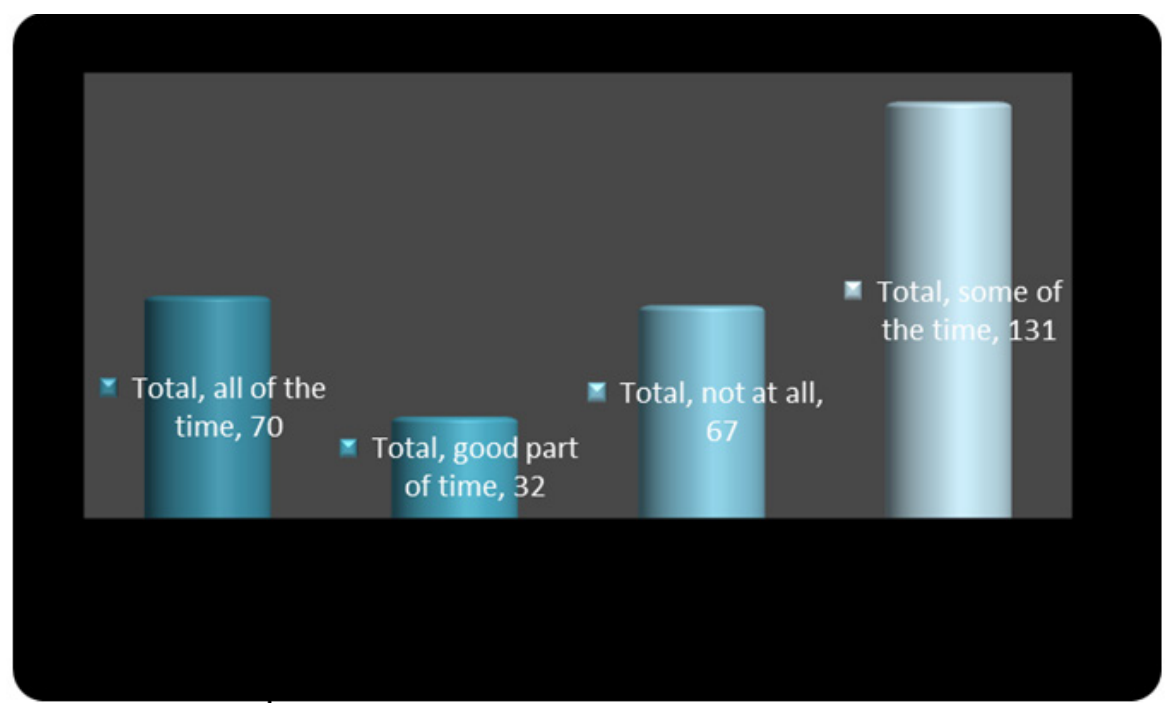

Figure 4 Feeling of depressed mood. 


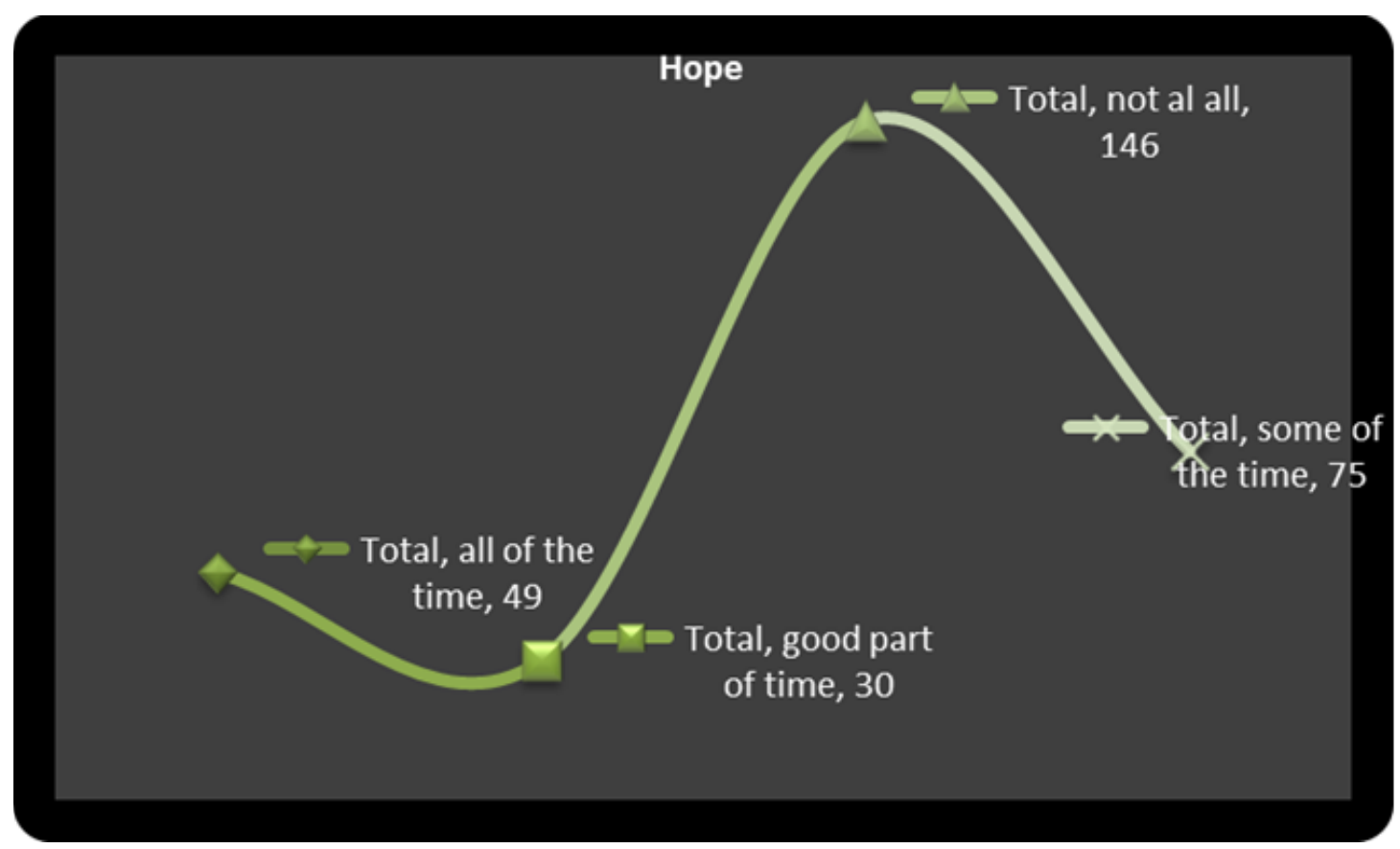

Figure 5 Level of individual hope.

\section{Task}

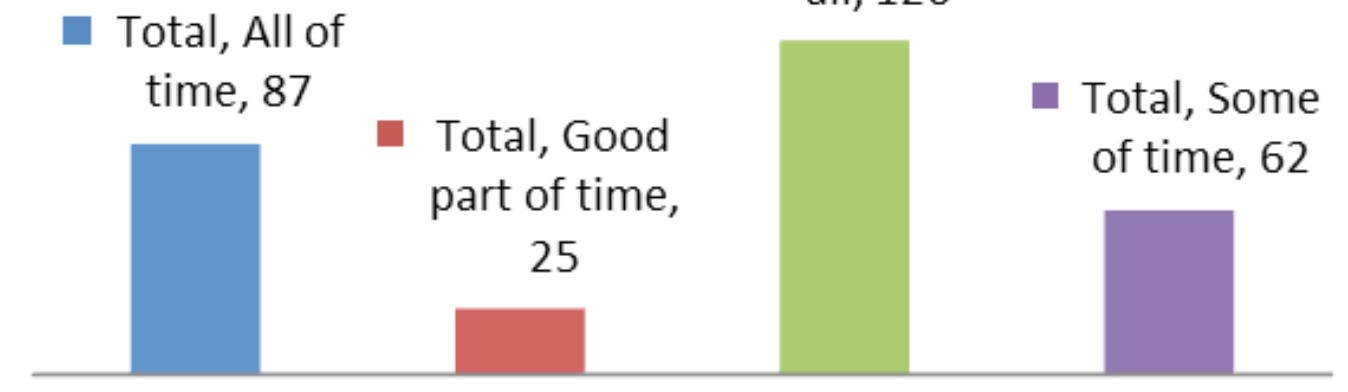

\section{Total, Not at \\ all, 126}

Figure 6 Task level.

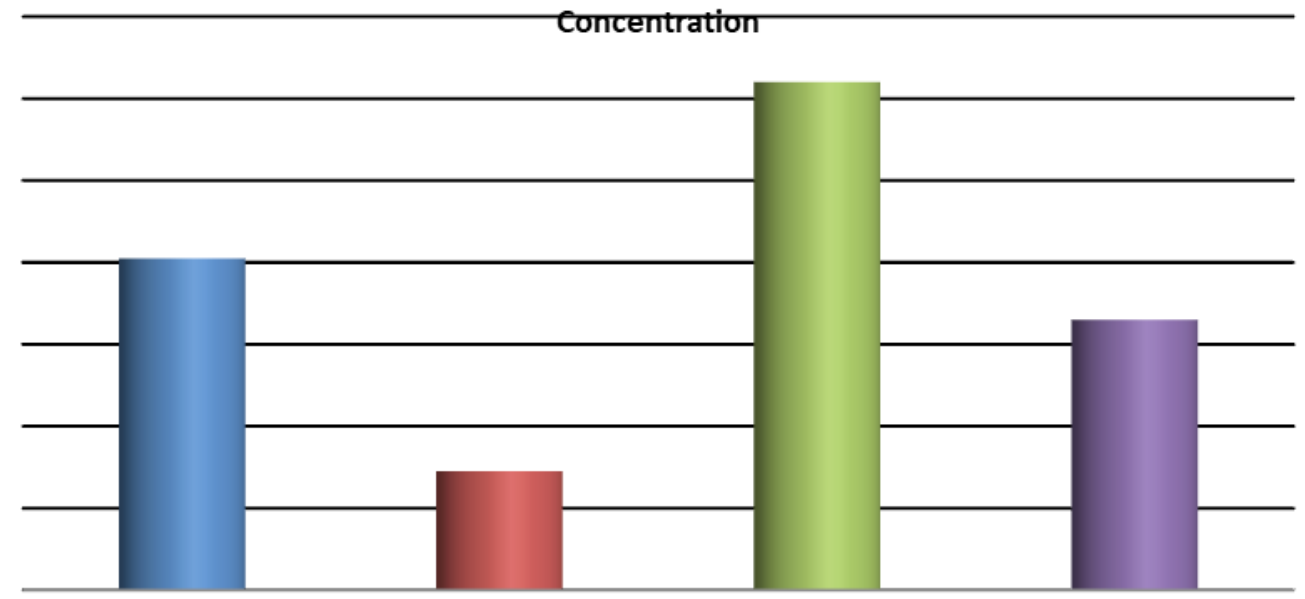

Figure 7 Level of concentration.

Citation: Suliman, Kabir A, lqbal Z, et al. Prevalence of melancholy in swat valley, Pakistan. MOJ Biol Med. 202 I;6(4):148-156. DOI: I0.15406/mojbm.202I.06.00148 
People were asked about their difficulty of making decision in which $38 \%$ of individual were in favor of depression while rest was not in favor of depression (Figure 8). To investigate further we asked about feeling of guilt, in which we found that $70 \%$ of individual does not feel guilt or either feel some of the time while reaming have feeling of guilt (Figure 9). To find out suicidal incidence that whether people attempt to take their life or not which gives us different result, in which 170 individual does not have any suicidal thoughts while 24 individual have suicidal thoughts all of the time (Figure 10).

\section{Decision}

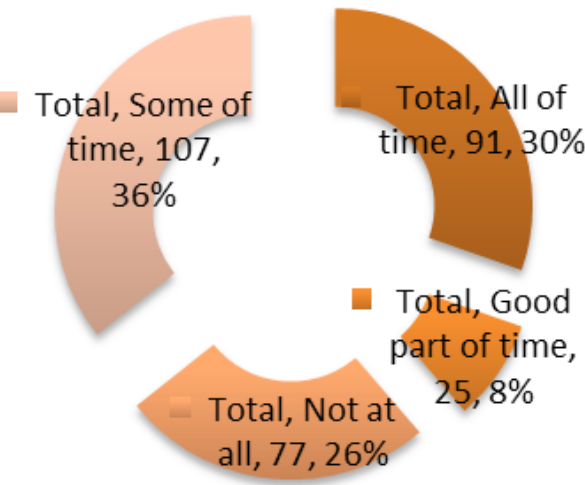

Figure 8 Taking decision.

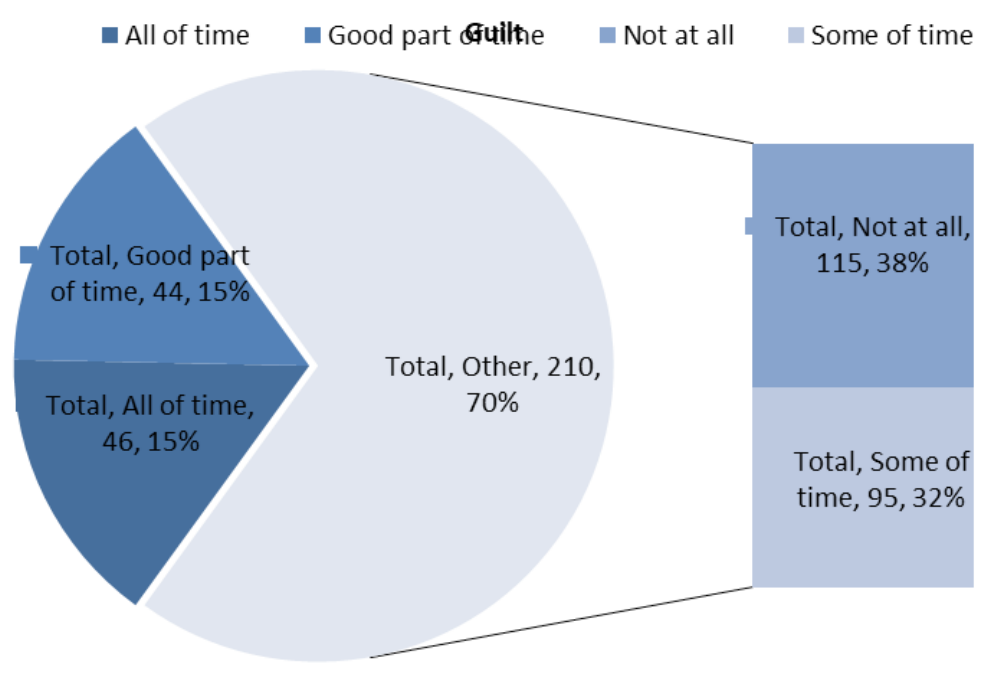

Figure 9 Individual feeling of guilt.

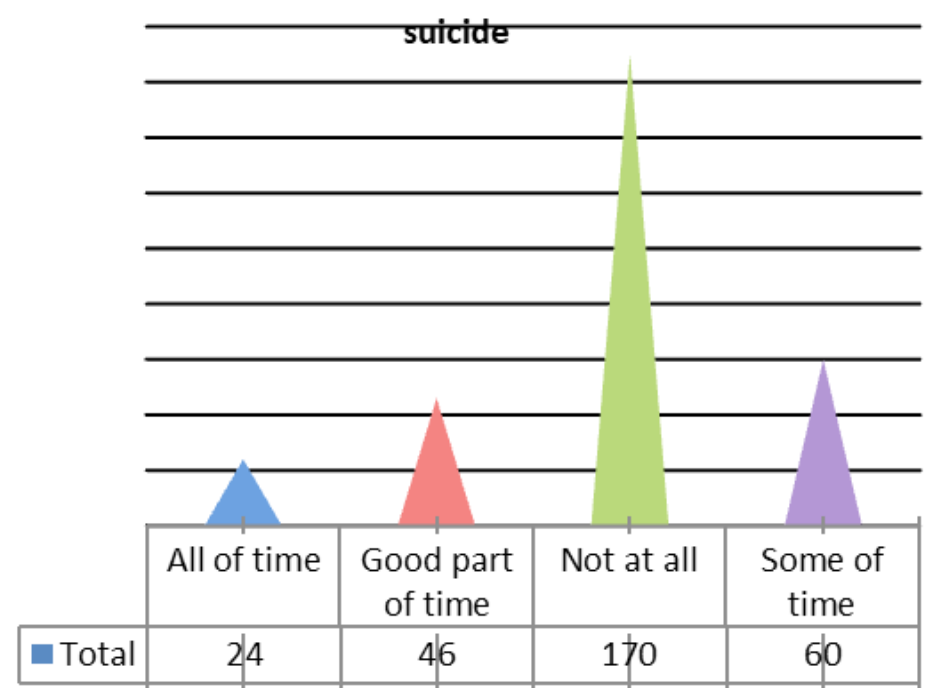

Figure 10 Suicidal thoughts. 
Along with that we asked that whether individual notice or experience their weight gaining or not and we found that $42 \%$ does not notice any gain and loss in their weight, remaining are shown in chart below (Figure 11). Moreover we know that depressed individual have feeling of tiredness, we noticed that some of the respondent show symptoms of tiredness in favor of depression while some does not agree strongly and some does not show at al see in scatter line (Figure
12). In similar manner for the precise evaluation of depression, we point out about headache without any physical reason, drugs that whether they use any particular drugs or not in the same way about level of enjoy to find out that the activity which was once enjoyable are the same or not, again loneliness to uncover that how much they are interested in being alone results were shown graphically (Figures $13 a, b, c \& d)$.

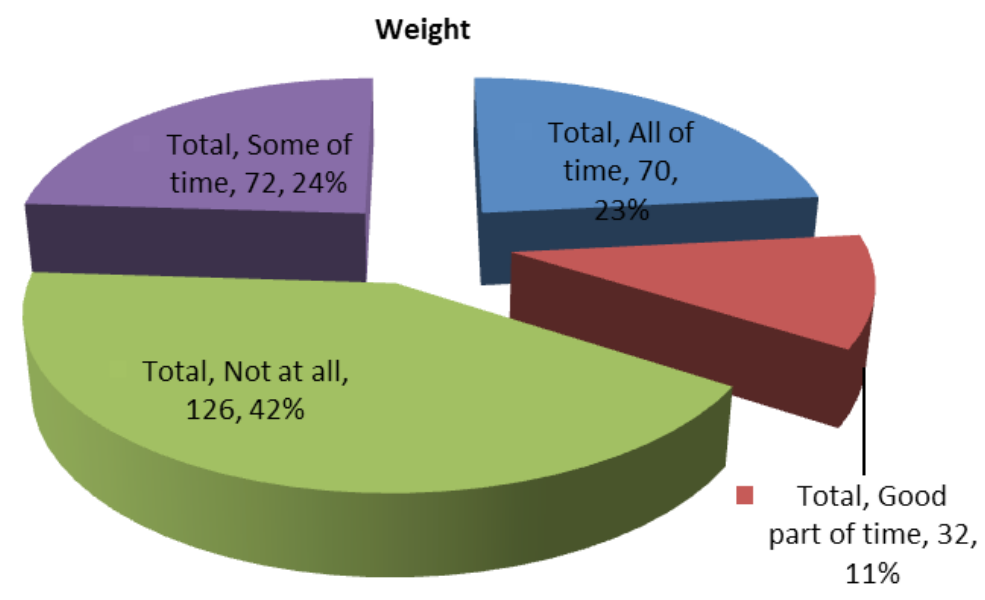

Figure I I Weight gaining.

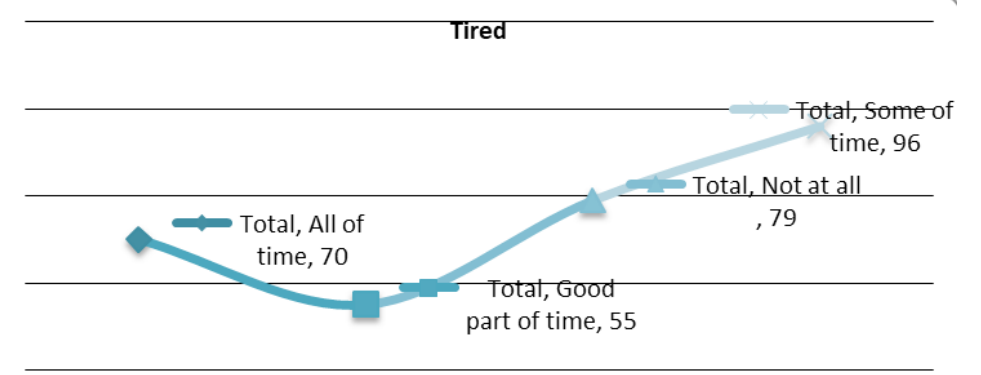

Figure 12 Tiredness of participants.

\section{Headaches}

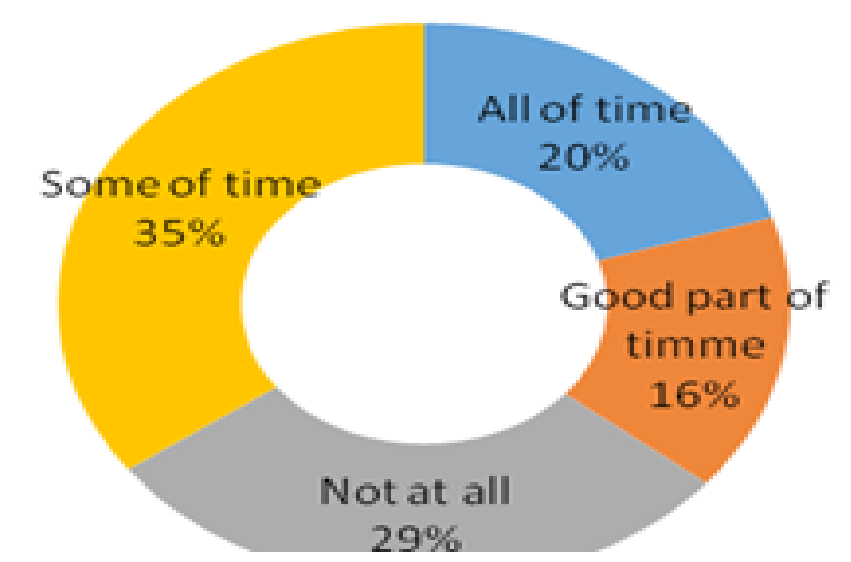

Figure 1 3a Headache of respondent. 


\section{all of time $\quad$ Good part of time $\quad$ Not at all $\quad$ Some of time}

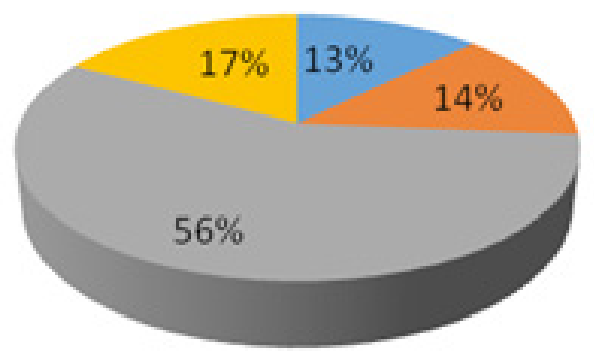

Figure I3b Enjoy status of individual.

\section{Drugs}

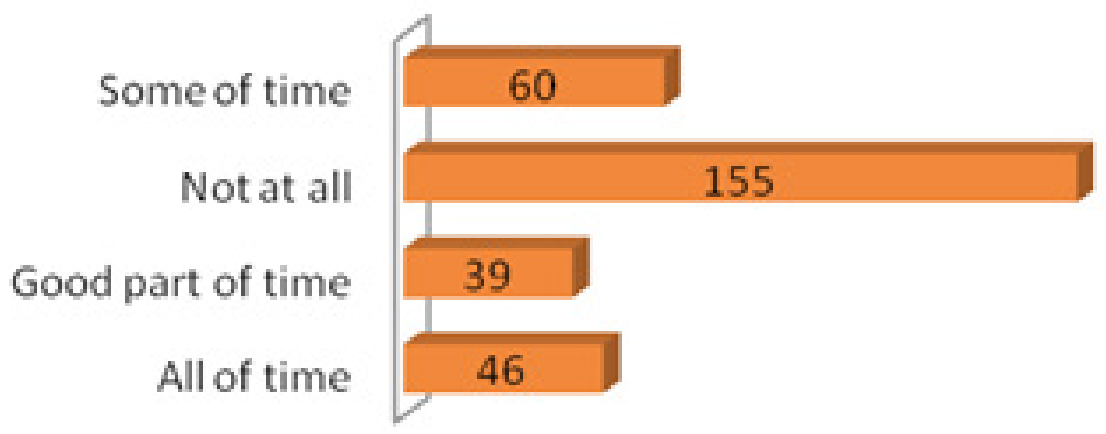

Figure 13c Individual use of drugs.

\section{Loneliness}

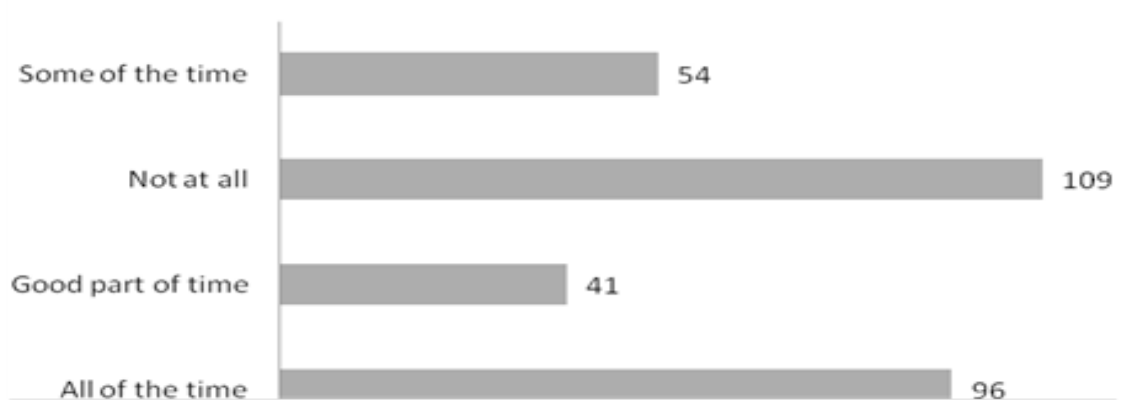

Figure 13d Loneliness level.

\section{Discussion}

This questionnaire based study was conducted in time period of 6 month, from January to June. In this time period all the 300 questioners were filled. We found that the number of depressed individuals were 145 and undepressed were 155 . In this research samples were collected across different gender including both males and females. Out of 106 females $20.6 \%$ were depressed while the number of depressed male were $27.6 \%$. Several studies have been conducted on mental disorder at the end of World War ${ }^{25}$ and almost in every population prevalence of depression are high. The most common mental problem in western world is depression. ${ }^{1}$ A study demonstrates higher prevalence of the depressive symptoms among females $(22.4 \%)$ than among males $(13.9 \%)$.
A positive response to (sad/depressed/down and loss of interest/ joy) was twice as prevalent in females $(15.8 \%)$ than males $(8.7 \%)$; 2) depressed mood "only" was also more common in females (3.9\%) than males $(2.6 \%) ; 3)$ but interestingly enough the difference was clinically insignificant with regard to loss of interest and/or joy "only" $(2.7 \%$ in females vs. $2.6 \%$ in males, $\chi 2=1.47, \mathrm{p}<0.06)$, which unfortunately were not assessed separately. On the basis of age all the participant were divided into 5 groups showing in table 4.1 Out of 300 samples the numbers of individual whose age vary between $10-20$ were $115(38.3 \%)$.in this age group the number of depressed individual were $45(15 \%)$. From age group 21-30 the number of depressed individual were $42(14 \%)$ out of 90 total individual. The respondent of age group 31-40 were 38 in which 20(6.6\%) were depressed. 29 samples 
were collected from age group 41-50 in which $5.3 \%$ people were depressed. Out of 28 samples the number of depressed individual were $22(7.3 \%)$ in the age group 51-60. Similar survey were perform in Vietnam in 2000 about the prevalence of depression in which $30 \%$ depressed were aged between $40-49$ years (Tran et al. 2002 ). A survey of 2,591 student age vary 12-18 in different schools in which mean depression score were $14.84(\mathrm{SD}=8.72)$. Males have less mean score of depressive symptoms (13.77) as compared to female which is 15.83 . $(26,27,28)$. The prevalence of depression and its relation to employment status we found that the number of employed individual were 14 in which $3 \%$ are depressed, while the number of unemployed individual were 286 in which depressed individual were $45.3 \%{ }^{26-28}$

A study was conducted involving 7,270 men and women showed inverse relation between employed grade and depressive symptoms, low level of employed status are more likely to depressed. ${ }^{29}$ ${ }^{33}$ According to another study recently conducted in France showed that the prevalence that the prevalence of depression is high in unemployed as compared to those people who work. ${ }^{34,35}$ In china find out link between work status and mental well being between new mother, he concluded that chance unemployed mother to get depressed are high and most of the time suffer from severe form of depression in a comparison with those who are employed. ${ }^{36-39}$

\section{Conclusion}

This study shows us the prevalence of depression in people of Tehsil khawaza khela. The overall prevalence found was $48.3 \%$. Males were depressed more than females with the prevalence rate of $(27.6 \%)$ and $(20.6 \%)$ respectively. On the basis of age-group 10-20 years were more depressed with the occurrence rate of $15 \%$. The most consistent symptoms found were less energy, difficulty in decision, effort for simple task.

\section{Recommendations}

a. One of the best ways to deal depression and recover from depression is to stay active.

b. Make and set small goal in your life and fell happy when you accomplish.

c. Take exercise regularly make and release some chemical that help you feel good.

d. Choosing diet wisely will boost your mental health

e. Get good night sleep every night don't disrupt your sleep cycle.

f. Take small manageable responsibilities to avoid worthlessness.

g. Try to stop negative thoughts and feeling about yourself and replace with good one.

h. Some of the cause of depression is hormonal, nutritional, chemical imbalances consult your doctor about this condition.

i. When you are depressed try to do something new visit new palace etc.

j. People need awareness about depression and their mechanism and how to fight them in form of seminar.

k. The best way of treatment is cognitive behavior therapy.

\section{Acknowledgments}

None.

\section{Conflicts of interest}

None.

\section{Funding}

None.

\section{References}

1. Erkanli A, Angold A, Costello EJ. Is there epidemic of child or adolescent depression? Journal of Child Psychology and Psychiatry. 2006;47(12):1263-1271.

2. Bentall P, Richard. The medicalisation of misery: A critical realist analysis of the concept of depression. Journal of mental health. 1999;8(3):261271.

3. Dhara Doshi R, Jogsan Yogesh A. Depression and psychological wellbeing in old age. Journal of Psychology \& Psychotherapy. 2013;3(3):1-7.

4. Goodwin Renee D, Ian H Gotlib. Gender differences in depression the role of personality Factors. Journal of Psychiatry research. 2004;126(2):135142.

5. Gotlib Hamilton I, H Paul J. Neuroimaging and depression: current status and unresolved issues. Current directions in Psychological Science. 2003;17(2):159-163.

6. Jayanthi P, Thirunavukarasu M. Prevalence of Depression among School Going Adolescents in South India. International Journal of Pharmaceutical and Clinical Research. 2015;7(1):61-63.

7. Revati R, Dudhatra, Jogsan A. Mental Health and Depression among Working and NonWorking Women. International Journal of Scientific and Research Publications. 2012;2(8):65-68.

8. Maurer Janet. Rebbapragada V, Borson Goldstein R, et al. Anxiety and depression in COPD: current understanding, unanswered questions, and research needs. Chest Journal. 2008;134(4):43-56.

9. Lakdawalla Z, Benjamin L, Hankin Mermelstein R, et al.Cognitive theories of depression in children and adolescents: A conceptual and quantitative review. Clinical child and family psychology review. 2007;10(1):1-24.

10. Goodman SH, Gotlib IH. Risk for psychopathology in the children of depressed mothers: a developmental model for understanding mechanisms of transmission. Psychological review. 1999;106(3)458-490.

11. Shonkoff MD, Duncan GJ, Yoshikawa H, et al. Maternal depression can undermine the development of young children. Centre on the developing child, Harvard University. 2009.

12. Read UM, Doku V. Mental health research in Ghana: a literature review. Ghana medical journal. 2012;46(2):29-38.

13. Sharma A, Sharma A, Yadava A. Parenting styles and depression among adolescent. 2011;137(1):60-68.

14. García VE, Villa SV, García Y. Post-myocardial infarction depression. In Anales de medicina interna. 2007;24(7):346-351.

15. Milin R, Walker S, Chow J. Major depressive disorder in adolescence: a brief review of the recent treatment literature. The Canadian Journal of Psychiatry. 2003;48(9):600-606.

16. Orth U, Robins RW, Roberts BW. Low self-esteem prospectively predicts depression in adolescence and young adulthood. Journal of personality and social psychology. 2008;95(3):695.

17. Espada JP, Sussman S, Medina TB, et al. Relation between substance use and depression among Spanish adolescents. International Journal of Psychology and Psychological Therapy. 2011;11(1):79-90.

18. Harinder S, Minhas S, Ahmed S, et al. A study of depression in geriatric population in a rural area of North India. Scholar Acad J Biosciences. 2015;3(1):26-29. 
19. Lennon MC, Blome J. Depression and low-income women: Challenges for TANF and welfare-to-work policies and programs. Research Forum on Children, Families, and the New Federalism, National Center for Children in Poverty, Mailman School of Public Health, Columbia University. 2001.

20. Cole HL, Ohanian LE. New Deal policies and the persistence of the Great Depression: A general equilibrium analysis. Journal of Political Economy. 2004;112(4):779-816.

21. Gabriel A, Violato C. Depression Literacy among Patients and the Public: A Literature Review. Primary Psychiatry. 2010;17(1):245-248.

22. Saleem M, Sattar S, Ismail RB. Link between Eating Disorders and Depression. Pakistan Journal of Commerce and Social Sciences. 2014;8(3):925-937.

23. Kharade SM, Gumate DS, NAIKWADE D. A review: hypothesis of depression and role of antidepressant drugs.Depression. 2010;15(16):1718

24. Singh A, Lal A, Singh S. Prevalence of depression among medical students of a private medical college in India. Online Journal of Health and Allied Sciences. 2011;9(4):222-225.

25. Cunningham S, Gunn T, Alladin A, et al.. Anxiety, depression and hopelessness in adolescents: a structural equation model. Journal of the Canadian Academy of Child and Adolescent Psychiatry. 2008;17(3):137139.

26. Veleber DM, Templer DI. Effects of caffeine on anxiety and depression. Journal of Abnormal Psychology. 1984;93(1):120-121.

27. Ng CG. A review of depression research in malaysia. The Medical journal of Malaysia. 2014;69:42-45.

28. Levin J. Religion and mental health: Theory and research. International Journal of Applied Psychoanalytic Studies. 2010;7(2):102-115.

29. Stewart DE, Robertson E, Dennis CL, et al. Postpartum depression: Literature review of risk factors and interventions. Toronto: University Health Network Women's Health Program for Toronto Public Health. 2003;1-60.
30. Patterson DR, Everett JJ, Bombardier CH, et al. Psychological effects of severe burn injuries. Psychological Bulletin. 1993;113(2):362-365.

31. Joseph S, Linley PA, Harwood J, et al. Rapid assessment of well-being: The Short Depression-Happiness Scale (SDHS). Psychology and psychotherapy: Theory, research and practice. 2004;77(4):463478.

32. Vangberg HCB, Lillevoll KR, Waterloo K, et al.. Does personality predict depression and use of an internet-based intervention for depression among adolescents. Depression research and treatment. 2012;1-43.

33. Al-Qaisy LM. The relation of depression and anxiety in academic achievement among group of university students. International Journal of Psychology and Counselling. 2011;3(5):96-100.

34. Barrett A. Depression and Its Relationship to Physical Activity and Obesity (Doctoral dissertation, The Ohio State University. 2012.

35. Hunsley J, Elliott K, Therrien Z. The efficacy and effectiveness of psychological treatments. Ottawa (ON): Canadian Psychological Association. 2013.

36. Anderson DM, Cesur R, Tekin E. Youth depression and future criminal behavior. Economic Inquiry. 2015;53(1):294-317.

37. Hammen C. Adolescent depression: Stressful interpersonal contexts and risk for recurrence. Current directions in psychological science. 2009;18(4):200-204.

38. Jayanthi P, Thirunavukarasu M, Rajkumar R. Academic stress and depression among adolescents: a cross-sectional study. Indian Pediatr. 2015;52(3):217-219.

39. Kurdyak P. The Impact of Depression on Outcomes Following Acute Myocardial Infarction (Doctoral dissertation). 2009.

40. Moreno MA, Jelenchick LA, Egan KG, et al. Feeling bad on Facebook: Depression disclosures by college students on a social networking site Depression and anxiety. 2011;28(6):447-455. 